\title{
Hepatic resection associated with good survival for selected patients with multinodular hepatocellular carcinoma
}

\author{
Jian-Hong Zhong • Fei-Xiang Wu • Hang Li
}

Received: 15 August 2014 / Accepted: 28 August 2014 / Published online: 9 September 2014

(C) International Society of Oncology and BioMarkers (ISOBM) 2014

As the sixth most common cancer and the third leading cause of cancer-related deaths worldwide, hepatocellular carcinoma (HCC) imposes a significant burden on health care [1]. The geographical distribution of HCC is extremely uneven. Despite the increased frequency of surveillance programs, the majority of patients have an intermediate or advanced stage $\mathrm{HCC}$ at diagnosis due to no significant symptoms in early stage. Of these, quite a number of them are with multinodular HCC $(\geq 2)$. It is therefore vital to choose the most effective and appropriate therapy for these patients.

Hepatic resection (HR) is the standard therapy for early stage HCC in non-cirrhotics with a well-preserved liver function [2]. However, the role of HR in the treatment of multinodular HCC remains controversial. According to the widely used Barcelona Clinic liver cancer (BCLC) staging system [3] and its updated review [4], HR should not be recommended to the patients with multinodular HCC [3]. Although the recommendations of BCLC staging system are endorsed by the American Association for the Study of Liver Diseases (AASLD) [5] and the European Association for the Study of the Liver (EASL) [6], many large and qualified liver centers in treating HCC especially those in Asia do not subscribe to these guidelines. Some retrospective studies have demonstrated that HR is superior to palliative treatments for

Jian-Hong Zhong and Fei-Xiang Wu contributed equally to this work.

J.-H. Zhong $(\bowtie) \cdot$ F.-X. Wu

Hepatobiliary Surgery Department, Affiliated Tumor Hospital of Guangxi Medical University, He Di Rd. \#71, Nanning 530021,

People's Republic of China

e-mail: zhongjianhong66@163.com

H. Li $(\bowtie)$

Ultrasound Department, Affiliated Tumor Hospital of Guangxi

Medical University, He Di Rd. \#71, Nanning 530021,

People's Republic of China

e-mail: lihang0123456@126.com multinodular HCC [7-10]. Although these retrospective studies may have some unintentional selection bias, the first randomized controlled trial (RCT) by Yin and coworkers definitely support this conclusion [11]. These studies highlight one of the ongoing controversies that surround the BCLC system.

The fact that AASLD/EASL guidelines do not recommend HR for patients with intermediate or advanced stage HCC reflects primarily concerns over high recurrence and perioperative mortality, rather than direct prospective clinical evidence. However, recent advances in perioperative management and surgical techniques, as well as more restrictive selection of patients for HR, have rapidly reduced perioperative mortality, which was only $1.1 \%$ in the RCT [11]. Moreover, HR can achieve satisfactory overall survival [12] in patients with recurrent HCC. Aggressive treatment of recurrence by repeat HR, radiofrequency ablation (RFA), and adjuvant therapies, such as transarterial chemoembolization (TACE), can offer satisfactory overall survival (OS) [13-15]. Therefore, this trial and other retrospective studies concluding HR superior to TACE makes sense [7-9, 11].

RCTs directly comparing TACE and HR in such patients have been lacking because clinicians are loathe to treat them exclusively with TACE, given the demonstrated survival benefit of HR in many retrospective studies [7-9]. For this reason, this RCT [11] stands out as providing clear, direct evidence against current guidelines. Therefore, it is a very valuable study.

This RCT was conducted on 173 patients with multinodular HCC outside of Milan criteria who were treated in a big liver center in eastern China. The patients were included in a short time period from 2008 to 2010 and underwent intention-to-treat analysis. Most of the included patients $(91.3 \%)$ were positive for hepatitis B surface antigen and with cirrhosis $(82.7 \%)$. There were no significant differences in the 30-day and in the 90-day mortality between the 
Table 1 Efficacy of transarterial chemoembolization for Asian patients with BCLC-B/C hepatocellular carcinoma

\begin{tabular}{|c|c|c|c|c|c|c|c|}
\hline \multirow[t]{2}{*}{ Study } & \multirow[t]{2}{*}{ Recruitment period } & \multirow[t]{2}{*}{ Sample size } & \multirow[t]{2}{*}{ Tumor characteristics } & \multirow[t]{2}{*}{ Median survival, months } & \multicolumn{3}{|c|}{ Overall survival } \\
\hline & & & & & 1 year & 2 years & 3 years \\
\hline Yin et al. 2014 [11] & 2008-2010 & 87 & Beyond Milan criteria & 14 & 52 & 35 & 18 \\
\hline Hsu et al. 2012 [16] & $2002-2010$ & 455 & Beyond Milan criteria & - & 68 & 45 & 30 \\
\hline Lo et al. 2002 [17] & 1996-1997 & 40 & $7 \mathrm{~cm}$ (range, 4-14) & - & 57 & 31 & 26 \\
\hline Takayasu et al. 2006 [18] & 1994-2001 & 2,076 & $\geq 5.1 \mathrm{~cm}$ & - & 63 & - & 30 \\
\hline Takayasu et al. 2012 [19] & $2000-2005$ & 811 & $\geq 5.1 \mathrm{~cm}$ & - & 77 & - & 44 \\
\hline Zhong et al. 2014 [7] & 2000-2007 & 351 & $10 \mathrm{~cm}$ (range, 4-20) & 24 & 81 & 48 & 33 \\
\hline
\end{tabular}

HR and TACE groups. However, the HR group had significantly better OS than the TACE group $(P<0.001)$. The 1-, 2-, and 3 -year OS and median survival were 76,64 , and $52 \%$ and 41 months, respectively, in the HR group. The trial did not report the 5-year OS.

Though this is a well-conducted RCT that challenges current thinking about the appropriateness of HR for patients with multinodular HCC, the evidence of this RCT suffers from important weaknesses. First, median 3-year survival in their TACE cohort was 14 months (range, 5-47 months), and OS at 1,2 , and 3 years was 52, 35, and $18 \%$, respectively. These survival rates are significantly lower than those reported in other large retrospective studies of Asian cohorts [7, 16-19] (Table 1). The authors [11] attribute this discrepancy to the fact that their TACE patients had larger tumors than those of similar cohorts in other studies [7, 16-19], yet other studies

Table 2 In-hospital mortality and survival of patients with multinodular hepatocellular carcinoma after hepatic resection

\begin{tabular}{|c|c|c|c|c|c|c|c|c|c|c|}
\hline \multirow[t]{2}{*}{ Study } & \multirow{2}{*}{$\begin{array}{l}\text { Enrollment } \\
\text { period }\end{array}$} & \multirow{2}{*}{$\begin{array}{l}\text { Total } \\
\text { patients }\end{array}$} & \multirow{2}{*}{$\begin{array}{l}\text { In-hospital } \\
\text { mortality, \% }\end{array}$} & \multirow{2}{*}{$\begin{array}{l}\text { Median survival, } \\
\text { months }\end{array}$} & \multicolumn{3}{|c|}{ Overall survival, $\%$} & \multicolumn{3}{|c|}{ Disease-free survival, $\%$} \\
\hline & & & & & 1 year & 3 years & 5 years & 1 year & 3 years & 5 years \\
\hline \multirow[t]{2}{*}{ Cheung et al. 2010 [20] } & \multirow[t]{2}{*}{$2001-2006$} & 19 & 5.3 & 53 & 89 & 63 & 63 & 45 & 30 & 30 \\
\hline & & 54 & 5.6 & 45 & 89 & 52 & 39 & 48 & 35 & 30 \\
\hline Choi et al. 2007 [21] & 1999-2006 & 53 & 3.8 & 67 & 87 & 80 & 55 & 41 & 28 & 0 \\
\hline Choi et al. 2011 [22] & 1996-2006 & 17 & - & - & 65 & 37 & 37 & - & - & - \\
\hline Choi et al. 2013 [8] & 2003-2008 & 36 & - & - & 92 & 83 & 48 & 60 & 30 & 11 \\
\hline Goh et al. 2014 [23] & 2000-2011 & 110 & 1.8 & 80 & 82 & - & 44 & 57 & - & 19 \\
\hline Ho et al. 2009 [9] & $1981-2000$ & 294 & - & 38 & 77 & 52 & 37 & 61 & 32 & 25 \\
\hline Huang et al. 2010 [24] & 2003-2005 & 26 & 0 & - & 92 & 81 & 69 & - & - & - \\
\hline Ikai et al. 2007 [25] & $1992-2003$ & 3,174 & - & - & 75 & 48 & 30 & - & - & - \\
\hline \multirow[t]{3}{*}{ Ishizawa et al. 2008 [26] } & \multirow[t]{3}{*}{ 1994-2004 } & 105 & 0 & - & - & 72 & 58 & - & 27 & 25 \\
\hline & & 21 & 0 & - & - & 33 & 19 & - & 13 & 0 \\
\hline & & 60 & 10 & 22.6 & - & - & - & - & - & - \\
\hline Jiang et al. 2014 [27] & 2007-2012 & 33 & 0 & - & 85 & 64 & 51 & 55 & 36 & 20 \\
\hline Kim et al. 2013 [28] & 1992-2011 & 46 & 7 & 70 & 78 & 59 & 53 & 53 & 30 & 27 \\
\hline Liu et al. 2003 [29] & 1989-2000 & 15 & 0 & 19.5 & 62 & 37 & 15 & - & - & - \\
\hline Luo et al. 2011 [30] & 2004-2006 & 85 & 2.4 & 22.5 & 71 & 35 & 24 & - & - & - \\
\hline Nojiri et al. 2014 [31] & 1992-2011 & 107 & - & - & - & 62 & 38 & - & 44 & 31 \\
\hline Ramacciato et al. 2010 [32] & 2000-2006 & 20 & 15 & 23 & - & - & 34 & - & - & 0 \\
\hline Ruzzenente et al. 2009 [12] & $1991-2007$ & 72 & - & 11 & - & - & 15 & - & - & - \\
\hline Utsunomiya et al. 2000 [33] & 1990-1998 & 34 & - & - & 92 & 75 & 25 & 72 & 24 & 24 \\
\hline Wang et al. 2008 [34] & 1990-2006 & 112 & 2.7 & 47 & 86 & 56 & 30 & 46 & 29 & 18 \\
\hline Yang et al. 2009 [35] & 1992-2002 & 86 & 2.3 & 14.9 & 78 & 29 & 20 & 63 & 32 & 18 \\
\hline Yin et al. 2014 [11] & 2008-2010 & 88 & 1.1 & 41 & 76 & 52 & - & - & - & - \\
\hline Zhong et al. 2014 [7] & 2000-2007 & 278 & 2.7 & 51 & 91 & 62 & 41 & - & - & - \\
\hline
\end{tabular}

En dashes indicate data not reported 
involving similarly large tumors in fact showed better OS (Table 1). It seems quite possible that the results of this trial reflect the presence of confounding factors in their TACE cohort. Although the TACE and HR patient groups did not show any statistically significant differences in baseline characteristics, risk factors for poor prognosis were more prevalent in the TACE group: TACE patients tended to be older than HR patients (54.0 vs. 51.6 years), to show higher incidence of cirrhosis ( 87 vs. $78 \%$ ) and Child-Pugh B liver function (5.9 vs. $1.1 \%$ ), and to have larger tumors (10.4 vs. $9.5 \mathrm{~cm})$. These characteristics together may have contributed to the relatively low OS in the TACE cohort, and they call into question the generalizability of the study's conclusions for patients with multinodular HCC.

Further complicating interpretation of the survival outcomes in the RCT is the fact that although TACE is one of the primary methods for treating recurrent $\mathrm{HCC}$, none of the 52 patients in the HR group who suffered intrahepatic recurrence (including 12 who suffered both intra- and extrahepatic recurrence) was treated with TACE. Moreover, although the authors themselves indicated in the methods section their intention to administer sorafenib to patients with extrahepatic recurrence, only five of 22 such patients ( $23 \%$ ) actually received this therapy.

Therefore, unintentional selection bias may also exist. The efficacy of HR may be amplified. In addition, because the indications for HR in Asia are broader than specified by the BCLC, it is easier to compare outcomes in patients with multinodular HCC who were treated with HR or TACE. A comprehensive review in the same topic may help to solve these problems.

After systematically searched PubMed database, 21 studies involving a total of 4,945 patients with multinodular HCC who underwent initial HR were included into analysis [7-9, $11,12,20-35]$. All the 21 studies were published after January 2000 and in English (Table 2). Almost all the included patients were with preserved liver function. The median

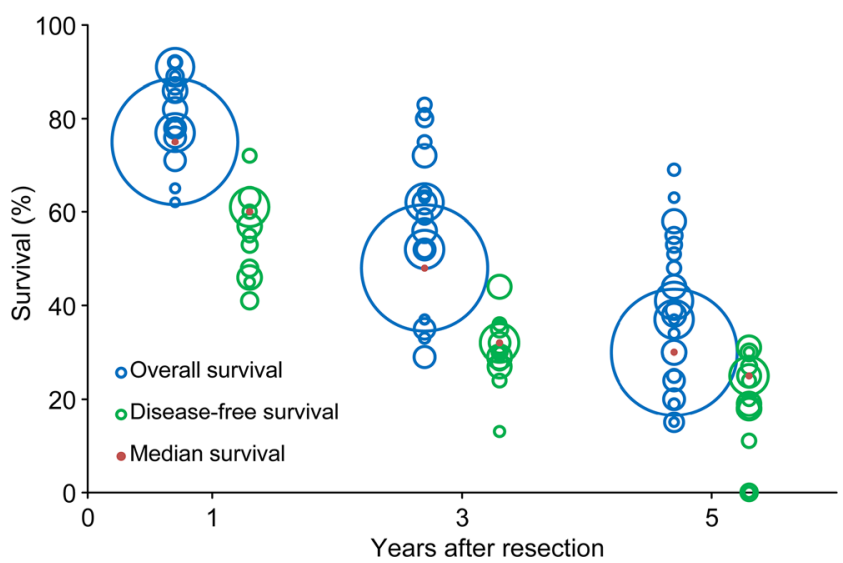

Fig. 1 The median 1-, 3-, and 5-year OS and disease-free survival following HR mortality and survival were $2.7 \%(0-15.0 \%)$ and 41 months, respectively. The median 1-, 3-, and 5-year OS and disease-free survival following HR were 75,48 , and $30 \%$ and 60,32 , and $25 \%$ (Fig. 1). The median survivals of our comprehensive review and the RCT are similar [36].

The Asia-Pacific Association for the Study of the Liver [37], the Clinical Practice Guidelines for Hepatocellular Carcinoma (HCC) in Japan [38], the American HepatoPancreato-Biliary Association [39], and the Asian Oncology Summit 2009 [40] state that multifocality of tumor is not absolute contraindications to HR. The NCCN version 2.2014 guideline for hepatobiliary cancers recommends that limited and resectable multifocal HCC with no portal hypertension can be considered for HR [41]. Moreover, the combination of HR and intraoperative RFA widens the applicability of surgical intervention for patients with multinodular HCC [20, 21, 29]. Therefore, as long as HR is technically feasible and safe, HR was associated with good survival for selected patients with multinodular HCC.

Acknowledgments This study was supported by the Self-Raised Scientific Research Fund of the Ministry of Health of Guangxi Province (nos. Z2012345 and Z2014241) and Youth Science Foundation of Guangxi Medical University (no. GXMUYSF201302).

\section{References}

1. Jemal A, Bray F, Center MM, Ferlay J, Ward E, Forman D. Global cancer statistics. CA Cancer J Clin. 2011;61(2):69-90.

2. Lim KC, Chow PK, Allen JC, Siddiqui FJ, Chan ES, Tan SB. Systematic review of outcomes of liver resection for early hepatocellular carcinoma within the Milan criteria. Br J Surg. 2012;99(12): $1622-9$.

3. Forner A, Reig ME, de Lope CR, Bruix J. Current strategy for staging and treatment: the BCLC update and future prospects. Semin Liver Dis. 2010;30(1):61-74.

4. Bruix J, Gores GJ, Mazzaferro V. Hepatocellular carcinoma: clinical frontiers and perspectives. Gut. 2014;63(5):844-55.

5. Bruix J, Sherman M. Management of hepatocellular carcinoma. Hepatology. 2005;42(5):1208-36.

6. European Association For The Study Of The Liver. EASL-EORTC clinical practice guidelines: management of hepatocellular carcinoma. J Hepatol. 2012;56(4):908-43.

7. Zhong JH, Ke Y, Gong WF, et al. Hepatic resection associated with good survival for selected patients with intermediate and advancedstage hepatocellular carcinoma. Ann Surg. 2014;260(2):329-40.

8. Choi SH, Choi GH, Kim SU, et al. Role of surgical resection for multiple hepatocellular carcinomas. World J Gastroenterol. 2013;19(3):366-74.

9. Ho MC, Huang GT, Tsang YM, et al. Liver resection improves the survival of patients with multiple hepatocellular carcinomas. Ann Surg Oncol. 2009;16(4):848-55.

10. Zhong JH, Xiang BD, Gong WF, et al. Comparison of long-term survival of patients with BCLC stage B hepatocellular carcinoma after liver resection or transarterial chemoembolization. PLOS ONE. 2013;8(7):e68193. 
11. Yin L, Li H, Li AJ, et al. Partial hepatectomy vs. transcatheter arterial chemoembolization for resectable multiple hepatocellular carcinoma beyond Milan Criteria: a RCT. J Hepatol. 2014;61(1):82-8.

12. Ruzzenente A, Capra F, Pachera S, et al. Is liver resection justified in advanced hepatocellular carcinoma? Results of an observational study in 464 patients. J Gastrointest Surg. 2009;13(7):1313-20.

13. Zhong JH, Li H, Li LQ, et al. Adjuvant therapy options following curative treatment of hepatocellular carcinoma: a systematic review of randomized trials. Eur J Surg Oncol. 2012;38(4):286-95.

14. Zhong JH, Ma L, Li LQ. Postoperative therapy options for hepatocellular carcinoma. Scand J Gastroenterol. 2014;49(6):649-61.

15. Zhong JH, Zhong QL, Li LQ, Li H. Adjuvant and chemopreventive therapies for resectable hepatocellular carcinoma: a literature review. Tumour Biol. 2014. [Epub ahead of print].

16. Hsu CY, Hsia CY, Huang YH, et al. Comparison of surgical resection and transarterial chemoembolization for hepatocellular carcinoma beyond the Milan criteria: a propensity score analysis. Ann Surg Oncol. 2012;19(3):842-9.

17. Lo CM, Ngan H, Tso WK, et al. Randomized controlled trial of transarterial lipiodol chemoembolization for unresectable hepatocellular carcinoma. Hepatology. 2002;35(5):1164-71.

18. Takayasu K, Arii S, Ikai I, et al. Prospective cohort study of transarterial chemoembolization for unresectable hepatocellular carcinoma in 8510 patients. Gastroenterology. 2006;131(2):461-9.

19. Takayasu K, Arii S, Kudo M, et al. Superselective transarterial chemoembolization for hepatocellular carcinoma. Validation of treatment algorithm proposed by Japanese guidelines. J Hepatol. 2012;56(4):886-92.

20. Cheung TT, Ng KK, Chok KS, et al. Combined resection and radiofrequency ablation for multifocal hepatocellular carcinoma: prognosis and outcomes. World J Gastroenterol. 2010;16(24):3056-62.

21. Choi D, Lim HK, Joh JW, et al. Combined hepatectomy and radiofrequency ablation for multifocal hepatocellular carcinomas: longterm follow-up results and prognostic factors. Ann Surg Oncol. 2007;14(12):3510-8.

22. Choi GH, Park JY, Hwang HK, et al. Predictive factors for long-term survival in patients with clinically significant portal hypertension following resection of hepatocellular carcinoma. Liver Int. 2011;31(4):485-93.

23. Goh BK, Chow PK, Teo JY, et al. Number of nodules, Child-Pugh status, margin positivity, and microvascular invasion, but not tumor size, are prognostic factors of survival after liver resection for multifocal hepatocellular carcinoma. J Gastrointest Surg. 2014;18(8):1477-85.

24. Huang J, Yan L, Cheng Z, et al. A randomized trial comparing radiofrequency ablation and surgical resection for HCC conforming to the Milan criteria. Ann Surg. 2010;252(6):903-12.

25. Ikai I, Arii S, Okazaki M, et al. Report of the 17th nationwide follow-up survey of primary liver cancer in Japan. Hepatol Res. 2007;37(9):676-91.

26. Ishizawa $\mathrm{T}$, Hasegawa $\mathrm{K}$, Aoki $\mathrm{T}$, et al. Neither multiple tumors nor portal hypertension are surgical contraindications for hepatocellular carcinoma. Gastroenterology. 2008;134(7):1908-16.
27. Jiang L, Liao A, Wen T, Yan L, Li B, Yang J. Living donor liver transplantation or resection for Child-Pugh A hepatocellular carcinoma patients with multiple nodules meeting the Milan criteria. Transpl Int. 2014;27(6):562-9.

28. Kim PT, Jang JH, Atenafu EG, et al. Outcomes after hepatic resection and subsequent multimodal treatment of recurrence for multifocal hepatocellular carcinoma. Br J Surg. 2013;100(11):1516-22.

29. Liu CL, Fan ST, Lo CM, Ng IO, Poon RT, Wong J. Hepatic resection for bilobar hepatocellular carcinoma: is it justified? Arch Surg. 2003;138(1):100-4.

30. Luo J, Peng ZW, Guo RP, et al. Hepatic resection versus transarterial lipiodol chemoembolization as the initial treatment for large, multiple, and resectable hepatocellular carcinomas: a prospective nonrandomized analysis. Radiology. 2011;259(1):286-95.

31. Nojiri K, Tanaka K, Takeda K, et al. The efficacy of liver resection for multinodular hepatocellular carcinoma. Anticancer Res. 2014;34(5): 2421-6.

32. Ramacciato G, Mercantini P, Petrucciani N, et al. Does surgical resection have a role in the treatment of large or multinodular hepatocellular carcinoma? Am Surg. 2010;76(11):1189-97.

33. Utsunomiya T, Shimada M, Taguchi KI, et al. Clinicopathologic features and postoperative prognosis of multicentric small hepatocellular carcinoma. J Am Coll Surg. 2000;190(3):331-5.

34. Wang BW, Mok KT, Liu SI, et al. Is hepatectomy beneficial in the treatment of multinodular hepatocellular carcinoma? J Formos Med Assoc. 2008;107(8):616-26.

35. Yang LY, Fang F, Ou DP, Wu W, Zeng ZJ, Wu F. Solitary large hepatocellular carcinoma: a specific subtype of hepatocellular carcinoma with good outcome after hepatic resection. Ann Surg. 2009;249(1):118-23.

36. Zhong JH, Ke Y, Wang YY, Li LQ. Liver resection for patients with hepatocellular carcinoma and macrovascular invasion, multiple tumors, or portal hypertension. Gut. 2014; [Epub ahead of print].

37. Omata M, Lesmana LA, Tateishi R, et al. Asian pacific association for the study of the liver consensus recommendations on hepatocellular carcinoma. Hepatol Int. 2010;4(2):439-74.

38. Kokudo N, Makuuchi M. Evidence-based clinical practice guidelines for hepatocellular carcinoma in Japan: the J-HCC guidelines. J Gastroenterol. 2009;44 Suppl 19:119-21.

39. Jarnagin W, Chapman WC, Curley S, et al. Surgical treatment of hepatocellular carcinoma: expert consensus statement. HPB (Oxford). 2010;12(5):302-10.

40. Poon D, Anderson BO, Chen LT, et al. Management of hepatocellular carcinoma in Asia: consensus statement from the Asian Oncology Summit 2009. Lancet Oncol. 2009;10(11):1111-8.

41. National Comprehensive Cancer Network (NCCN). NCCN Clinical Practice Guidelines in Oncology. 2014; Available from URL: http:// www.nccn.org/professionals/physician_gls/f_guidelines.asp. 